\title{
ANAPHORIC REFERENCE TO ENTITIES AND PLACES IN LITERAL AND METAPHORICAL CONTEXTS ${ }^{1}$
}

\author{
J. LACHLAN MACKENZIE \\ VU University Amsterdam
}

\begin{abstract}
This article reports on corpus research into the occurrence of from + anaphor. Developing distinctions derived from the typology of entities and qualities in Functional Grammar as well as the notion of metaphoricality found in the work of Lakoff, we find that in the syntactic context chosen for analysis the anaphor there is applied when the language-user conceives of the antecedent as a metaphorical place, whereas the occurrence of anaphoric it indicates a nonmetaphorical conceptualization. The suggestion is advanced that choice of anaphor could be used as a test for metaphoricality where the source domain is location or movement in space.
\end{abstract}

It is now well understood that when we use a referring expression, we refer to a phenomenon or set of phenomena in a mentally projected world (Frawley 1992: 24). There is a general, and usually implicit, assumption that the phenomena we refer to are all entities, defined by Frawley (1992: 68) as "relatively stable and atemporal discourse, ontological, and conceptual phenomena". This tacit equation of referent and entity had already been challenged, however, by Lyons (1977: 475 ff.), who argued that language users refer not only to entities but also to other types of phenomena, notably places and times. The standard definition of entities involves notions of spatial stability and of temporality; if place and time were themselves entities, that definition would become circular. This is indeed the essence of Zeno of Elea's paradoxical observation that "Everything is in place; this means that it is in something; but if place is something, then place itself is in something, etc." (as presented by Jammer 1954: 16).

1. This work was supported by a grant from the Spanish Ministry of Science and Innovation (HUM2007-62220, PI: M.A. Gómez-González). 
The present article rests on Lyons's assumption that entities and places are distinct kinds of phenomena, examining anaphoric reference to each kind of phenomenon in a representative sample of contemporary English. The central claim will be that the distinction between entity and place carries over from the literal into the metaphorical domain, and that the nature of the anaphoric reference can be used as a diagnostic for identifying true metaphoricality. The theoretical framework to be applied is that of Functional Grammar (FG; Dik 1997) enriched with Cognitive Linguistics (Lakoff 1987), very much in the spirit of Pérez and Ruiz de Mendoza (2001), who show how FG could profitably incorporate advances in cognitive and pragmatic analysis of language use. Before progressing to our argument, however, we must first further clarify the distinction between entities and non-entities.

This distinction is not immediately obvious in the languages of the world. This fact is attributable to the ubiquity of hypostatization, the linguistic procedure by which we regularly treat places as though they were entities. Thus noun phrases are regularly employed to identify places. Lyons (1977: 693) argues that in (1):

(1) I'll meet you at the car.

the car is "used indirectly to identify a place; i.e. the space that is occupied by the car". Mackenzie (1992: 255), developing this idea, suggests that the mentally projected world to which we refer should be seen as a space that contains entities. What counts as an entity and what as a place, or as a figure against the ground, will vary according to the viewer's goals: thus the prospective buyer of a house may conceptualize the building as a potential place to live (indeed English has specialized the word bome to indicate this view of a dwelling), whereas the real estate agent will typically classify it as an object, i.e. as a commodity to be sold.

FG has developed a four-way ontology of entities, building upon the work of Lyons (1977), to whom we owe the distinction of the first three orders. Entities that fulfil without reserve Frawley's above-mentioned definition are classified as 'first-order entities'. They are "relatively constant as to their perceptual properties", "are located, at any point in time, in [...] a three-dimensional space", and "are publicly observable" (Lyons 1977: 443). To refer to first-order entities in a language like English, we typically use noun phrases the head of which is a noun such as woman, tortoise, nose or lorry. Second-order entities are "events, processes, states-of-affairs [...] which are located in time and which, in English, are said to occur or take place, rather than to exist" (Lyons 1977: 443). Such 
entities are typically referred to by means of clauses, such as the italicized nonfinite clause in (2):

(2) I saw him come up the path to the house.

Yet English, like most but not all languages, also permits us to refer to a second-order entity by means of a noun phrase, headed by such 'abstract' nouns as arrival, error, excursion or contest, as in (3):

(3) We awaited the arrival of the honoured guests.

Second-order entities are similar to first-order entities in being located in time and place, but lack physical palpability, and, as Lyons (1977: 444) remarks, "the criteria for re-identification are less clear-cut". The nouns that denote secondorder entities in English are typically nominalizations of some sort.

Third-order entities differ sharply from the preceding types in being located in neither space nor time; they are unobservable, purely 'mental' phenomena: "they are entities of the kind that may function as the objects of such so-called propositional attitudes as belief, expectation and judgement" (Lyons 1977: 445). In English they are regularly expressed as finite clauses, as in (4):

(4) I cannot believe that it is already three o'clock.

but again there are nouns available, such as belief, idea, fact or bope, for the formation of noun phrases that refer to third-order entities.

Fourth-order entities, finally, are speech acts. ${ }^{2}$ This category is due to Hengeveld (1992: 7), who points out that, like second-order entities, they are located in space and time. They have been added to Lyons's three-way ontology because of their special status in linguistic communication. They are typically realized as full utterances, of the type that can be quoted in direct speech. In (5), the italicized object of say refers to a fourth-order entity:

(5) And then she said, "Where did you find that hat?"

2. As Functional Grammar has morphed into Functional Discourse Grammar (Hengeveld and Mackenzie 2006), further types of fourth-order entity have been proposed. The nature of these need not detain us here. 
Whereas third-order entities are such that, generally speaking, "true', rather than 'real', is more naturally predicated of them" (Lyons 1977: 445), fourth-order entities are assessed in terms of their felicity. Again, English has nouns such as statement, question or command that denote fourth-order entities, although these can generally also denote the third-order entity associated with the speech act in question:

(6) I could not hear that question (fourth-order entity).

(7) I would like to contest the presupposition of that question (third-order entity).

The four-way ontology of entities proposed in FG is summarized in Table 1.

\begin{tabular}{|l|l|l|}
\hline Order of entity & Criterion & Example nouns \\
\hline First-order entities & {$[ \pm$ existent $]$} & woman, tortoise, nose, lorry \\
\hline Second-order entities & {$[ \pm$ real] } & arrival, error, excursion, contest \\
\hline Third-order entities & {$[ \pm$ true] } & belief, idea, fact, bope \\
\hline Fourth-order entities & {$[ \pm$ felicitous] } & statement, question, command \\
\hline
\end{tabular}

Table 1. FG ontology of entities.

What, then, of non-entities? I wish to put forward the suggestion, already adumbrated by Weigand (1990: 100), that corresponding to each order of entity there is a corresponding order of non-entity. Non-entities not only differ from entities, they also depend upon the latter for their identification. As Strawson (1959: 37) pointed out, "places are defined only by the relation of things", and, more generally, non-entities indicate qualities of the entities to which they are assigned. An example of such a non-entity is the colour 'red', which 'exists' in our mentally projected world only as an abstraction from the perceived quality of blood, apples, the Liverpool football team's strip, etc. In English, the qualities of first-order, thirdorder and fourth-order entities are typically expressed as adjectives, although nominalization again allows the possibility of hypostatization, i.e. nominal expression; the qualities of second-order entities, which will play a central role in what follows, are typically expressed by means of adverbs and adpositions. 
Let us therefore distinguish four types of quality. Firstly, there are attributes, which apply to first-order entities, e.g. the intelligence of the pupil or the beight of Ben Nevis. A quality applying to a second-order entity will be termed a circumstance, e.g. the venue of a football match or the duration of the play. A third-order entity such as belief, hope, etc. is assessed in terms of its epistemic status, as in the plausibility of her assertion, the vanity of her bopes. Finally, the quality that applies to fourth-order entities may be termed style, as in the imperiousness of her order or the directness of bis statement. The four-way ontology of qualities in FG may be summarized as in Table 2.

\begin{tabular}{|l|l|l|}
\hline Type of quality & $\begin{array}{l}\text { Type of associated } \\
\text { entity }\end{array}$ & Example nouns \\
\hline Attribute & first-order entity & intelligence, beight, colour \\
\hline Circumstance & second-order entity & venue, duration, reason \\
\hline Epistemic status & third-order entity & plausibility, vanity, persuasiveness \\
\hline Style & fourth-order entity & imperiousness, directness, vigour \\
\hline
\end{tabular}

Table 2. FG typology of qualities.

Focusing now on expressions referring to places, we can classify them within the four-way ontology of qualities as referring to a type of circumstance. At this point, we need to remind ourselves of the distinction between reference and denotation (cf. Lyons 1977: 208). Let us repeat example (1):

(1) I'll meet you at the car.

The prepositional phrase at the car refers to a place, a circumstance of my meeting you. The noun car, however, has no reference in itself; rather, it serves to denote an entity. Whereas reference results from an action of the speaker, i.e. the formation of the prepositional phrase, the relationship of denotation between the word car and the concept 'car' is a virtual one. We may consequently regard denotation as reflecting conceptualization, whereas reference is more a matter of visualization: in forming the prepositional phrase at the car, the speaker is visualizing the entity as a place.

There is a range of expression types that is specialized in the denotation of places. Firstly, toponyms such as Hong Kong unsurprisingly serve to denote places; 
indeed we will return to this very place-name in discussing (17) below. Secondly, spatial adverbs such as upstairs or aloft and spatial prepositions such as under or near also denote places; Mackenzie (2001) has argued that in FG the great majority of spatial adpositions and spatial adverbs should be seen as forming a single lexical category Ad. Thirdly, there is a class of nouns which do not denote entities but places: there are relational nouns such as lee, right, centre, which denote a region or a place in relation to some entity, as in in the lee of the wind, to the right of the bouse, at the centre of the circle; then there are nouns such as bome and shade which differ from the corresponding nouns bouse and shadow in pinpointing a location rather than an entity; and finally there are certain nouns that denote parts of the body that are conceptualized as places rather than entities, such as navel or armpit, in contrast to leg or nose which are clearly entity-denoting. Finally, headless relative clauses introduced by where serve to denote a place, e.g. where I spent my summer.

Generally, reference and denotation coincide: we refer to places by means of a place-denoting form, and refer to entities with an entity-denoting form. This is clear from the following examples, which display an equative structure:

(8) The South of France was where I spent my summer.

(9) A CD-player was what I wanted for Christmas.

In (8) we see an equation of two places, just as in (9) we see an equation of two entities. One property of equative utterances is that the two referents that are equated must be of the same type: entities can only be equated with entities of the same type, and qualities similarly can only be equated with qualities of the same type:

(10) *The South of France was what I wanted for Christmas.

(11) *A CD-player was where I spent my summer.

As pointed out above, entities are seen, and indeed defined, as occupying places. As a result, each entity is associated with a place at any one moment, and conversely many places (though not all, because of the infinity of space) are associated with entities. These relations of association engender metonymic relations, which considerably expand the expression possibilities in language. Thus places may serve to identify the entities they contain, as in (12):

(12) Scotland were defeated in the European Championships.

where the first-order entity 'the Scottish team' is metonymically identified via the place with which the members of that team are associated; note how the verb 
agrees with the referent, understood as plural. Similarly, as we have already seen, entities may serve to identify the spaces they occupy; cf. the discussion of (1) above.

The sharp distinction between reference and denotation allows us to grasp that the lexical item car denotes an entity but is being used in (1) to refer to a place; and conversely, whereas Scotland denotes a place, it is being used in (12) to refer to an entity. A useful test was proposed by Thrane (1980: 92) to distinguish place-reference from entity-reference, the so-called of all test. Whereas reference to entities is generally identifiable by the possibility of appending the parenthetical expression of all things with non-human entities or of all people with human entities, reference to places permits the addition of parenthetical of all places. Applying this test to (8) and (9), we find indeed that this test applies to identify the subjects of those sentences as place-referring and entity-referring respectively:

(13) The South of France, of all places/*things, was where I spent my summer.

(14) A CD-player, of all things/*places, was what I wanted for Christmas.

The text also applies well to (12) and (1), where metonymy arises through a clash of reference and denotation:

(15) *Scotland, of all places, were defeated in the European Championships.

(16) *He proposed to meet me at the car, of all things. ${ }^{3}$

As shown in Figure 1, in addition to the straightforward correlations between denotation and reference, metonymy also permits the relations shown with dotted lines.

\begin{tabular}{|c|c|c|}
\hline Entity denotation & Entity reference \\
\hline Place denotation & &
\end{tabular}

Figure 1. Direct and metonymic relations between denotation and reference.

3. (16) is arguably well-formed, but only if of all things expresses surprise at the third-order entity 'his proposition'. The essential point is that the car here identifies a place, and therefore cannot trigger of all things. 
The two types of reference, reference to entities and reference to places, are reflected in the system of anaphoric pronouns in English. Although places are inanimate, reference to a previously mentioned place does not involve the pronouns for inanimate entities, but calls for the pronoun there. Interestingly, whereas anaphoric reference to an inanimate entity may be either demonstrative or not, in English there is no non-demonstrative pronoun for place-reference (compare Dutch, in which clitic er is the non-demonstrative equivalent of demonstrative daar). The system may be displayed as in Table 3.

\begin{tabular}{|l|l|l|}
\hline Anaphor to inanimate entity & Anaphor to place & \\
\hline it, they & (Dutch er) & -demonstrative \\
\hline that, this, these, those & there & +demonstrative \\
\hline
\end{tabular}

Table 3. Anaphoric reference to inanimate entities and places.

The metonymic relation between places and entities entails that the language user under certain circumstances has a choice between referring back to either the entity or the place. Consider the following example from the corpus examined in this article:

(17) Our casinos depend on Hong Kong, our exports depend on it and most of our tourists come from there. (MCA_IND1.FOR)

This example is remarkable in that the writer refers back to the place Hong Kong twice, first with the anaphor it, and then with the anaphor there. In the former case, the writer is visualizing Hong Kong as a commercial entity; in the latter, as a place where people live. Note that the choice of anaphor appears to be connected to the semantic context: the verb depend (on) selects for entity reference, whereas come selects for place reference.

The remainder of this article presents an examination of all the cases of pronominal anaphora to inanimate entities and to places introduced by the ablative preposition from, extracted from two corpora of modern English with a total of 4,100,659 words. The first is the MicroConcord Corpus $(2,107,134$ words). This corpus consists entirely of written material, half of it from the newspaper The Independent and the other half from books; both the newspaper subcorpus (A) and the books subcorpus (B) are further subclassified into 5 
genres each. ${ }^{4}$ References to this corpus will appear after relevant examples in the MicroConcord format: thus (MCA_IND1.FOR) indicates a reference to subcorpus A, Independent group 1, genre Foreign News. The second is the BNC Sampler (1,993,525 words), consisting of 185 texts, with an approximately equal division into written English and transcriptions of speech; many different genres are represented. ${ }^{5}$ References to this corpus are given in the BNC Sampler format, so that (BNC fxr 0340), for example, indicates text 'f $x r$ ', utterance no. 0340.

In total there are 424 relevant instances of pronominal anaphora introduced by from in the two corpora. The distribution is as shown in Table 4 . Note that only the use of this, that, these and those as pronouns was included, all cases of determiner use of these words being discarded.

\begin{tabular}{|l|l|l|l|}
\hline Item & MicroConcord Corpus & BNC Sampler & Total \\
\hline from there & 12 & 45 & 57 \\
\hline from it & 42 & 45 & 87 \\
\hline from them & 32 & 24 & 56 \\
\hline from this & 40 & 16 & 56 \\
\hline from that & 55 & 55 & 110 \\
\hline from these & 4 & 2 & 6 \\
\hline from those & 39 & 13 & 52 \\
\hline Total & 224 & 200 & 424 \\
\hline
\end{tabular}

Table 4. Distribution of relevant anaphors across the two corpora.

The choice of the preposition from was justified by a number of linked considerations. Firstly, it is a relatively frequent preposition and therefore likely to generate sufficient instances. Secondly, it is used in spatial contexts (He leapt from his bed, She is from Cornwall, etc.) and also in more abstract contexts (a necklace made from coral, knowledge from books, they suffer from malnutrition, etc.). Thirdly, whereas many prepositions are highly polysemic, from tends to retain

4. This corpus is no longer commercially available; to search the MicroConcord Corpus, see http://langbank.engl.polyu.edu.hk/corpus/microconcord.html (accessed on 2 June 2007).

5. This corpus is no longer commercially available; to search the BNC Sampler, see http:// langbank.engl.polyu.edu.hk/corpus/bnc_sampler.html (accessed on 2 June 2007). 
some sense of ablativity in all of its uses. Following Lakoff's (1987: 283) "spatialization of form" hypothesis, I will take the localist position ${ }^{6}$ that the spatial use of the preposition is basic, and will accordingly refer to such uses as 'literal'; the more abstract senses will be analysed as 'metaphorical'.

Of the 424 instances in the two corpora, 57 (13.4\%) involved place reference, i.e. took the form from there. In many cases, there was literal anaphoric or exophoric reference to a place, as in the following examples:

(18) go down the M50 into Ross and then go from there (BNC kcl O089)

(19) the place is like Fort Knox at the moment ... because someone was pilfering from there (BNC fxr 0340)

(20) where that stove was ... and they moved the sink from there (BNC kb2 0987)

(21) literally aiming the weapon and from there the gun was out (BNC jjw 0582)

(22) She couldn't see it from there. (BNC kdO 00783)

(23) she ripped it from there to there (BNC kdn 0041)

In (18) to (20) the antecedent clearly denotes a place: in (18) we find the toponym Ross, in (19) the (obviously!) place-denoting noun place, and in (20) a clause introduced by where. In (21), there appears to refer back to a rather vaguely specified bodily position and in (22), the place referred back to is clear only from the conversational context, with (23) showing, as the context makes plain, exophoric reference to two locations on the speaker's body.

In other cases, the antecedent appears to be an entity; in (24) a tent, in (25) a brew house and in (26) a university:

(24) went into one tent ... and carried from there the silver (BNC flu 004)

(25) in the brew house and then er where did I go from there? (BNC g4n 0087)

6. See the pioneering work of Anderson (1971: 128-150) on 'abstract direction'. 
(26) at the University of North Carolina. From there he and his wife ... (MCA_IND4.HOM).

Note, however, that the antecedent entity is in each case introduced by a spatial preposition (into, in, at respectively). It is as though the entity comes to be visualized as a place under the influence of this preposition, so that there does not really refer back to the entity 'tent', etc. but to the location evoked by the combination of preposition and entity-denoting noun. This appears to apply especially to entities that are metaphorical 'containers' of human activity such as businesses, restaurants and colleges. Some evidence for this analysis can be gained from instances in which the antecedent of there is clearly the entire prepositional expression:

(27) ... near the window. It has never moved from there because ... (BNC j8g 0630)

In this case, which is about the placement of a television set, there refers anaphorically to the prepositional phrase near the window.

All the instances considered above involved anaphoric reference to a literal place. However, from there can also be used in metaphorical contexts. Consider the familiar experientially based metaphors MORE IS UP, LESS IS DOWN (Lakoff 1987: 276) and GOOD IS UP, BAD IS DOWN (Lakoff and Johnson 1980: 16). These are clearly at work in (28) and (29) respectively:

(28) Are you gonna take the figure starting from one twenty and take it up from there and down from there (BNC $f 7 j$ 0781)

(29) The year began badly and went down from there (MCA_IND3.SPO)

The fact that there is here being used non-literally strengthens the case for regarding the conceptualization underlying the antecedent as also being metaphorical.

Let us consider other cases of metaphorical there, all of which involve the notion of Source - Path — Goal, i.e. a journey:

(30) So what's your next step from there? (BNC fm4 0883)

(31) So it'd have been twenty years and er from there I became er an instructor (BNC jjw 0223) 
(32) You don't WP from there (BNC jjw 0223)

(33) And then we was able to buy a little machine and it went from there (BNC g4n 0096)

(34) Now there's a serious point from starting from there because ... (BNC fly 0102)

(35) ... I got a feeling that this was really where ... I would be able to work. So from there I mentioned it to our provincial who's ... the one in charge of us ... and she said ... (BNC fy8 0062)

(36) I think the story is that, Matthew heard this voice, shall we just read from there? Mhm. Because then Jesus said to him, ... (BNC kbx 0180)

As Lakoff (1987: 435) points out, there is a very general metaphor ACTIVITY is A JOURNEY, of which we see various manifestations here. (30) shows LIFE IS A JOURNEY (Lakoff 1987: 439), and (31) a variant, CAREER IS A JOURNEY. Similarly, (32) and (33) show more specific activities metaphorized as journeys: OPERATING A COMPUTER IS A JOURNEY and OPERATING A BUSINESS IS A JOURNEY respectively. (34) displays AN ARGUMENT IS A JOURNEY (Lakoff and Johnson 1980: 89-96); (35) can be seen as exemplifying A NARRATIVE IS A JOURNEY and (36) as instantiating READING A TEXT IS A JOURNEY, both of which reflect a more general view that DISCOURSE SPACE IS PHYSICAL SPACE (cf. Lakoff 1987: 517-518, which indeed mentions the use of there to refer to "discourse in the immediate past").

What has emerged from our examination of the use of from there is that the antecedent can in all cases be identified as a location. However, whereas the instances (18-27) all exemplify a literal location, (28-36) show metaphorical locations, involving either experientially based cognitive metaphors of verticality or various interlinked metaphors in which from there is identified as the startingpoint of a journey. The fact that the locational anaphor there is used in these cases strengthens the case for asserting the all-pervasiveness of such metaphors in our everyday thinking and speech.

Non-demonstrative anaphoric reference to an entity calls in the corpus for the forms from it or from them. We will here concentrate on instances of from it. A typical example is (37):

(37) "What would you do if you saw a ferocious tiger walking across the playground?" "I'd escape from it riding like the wind on a champion racehorse" ... (BNC chr 0781) 
In discussing (24-26) above, we observed that there can be used to refer back to the location evoked by an entire prepositional phrase. Example (38), however, shows that anaphoric reference is also possible to the entity that is invoked by the complement of the preposition:

(38) She rested on the boulder and from it looked down to where the river ran shallow (BNC aea 1002)

where it refers back to the entity 'boulder' and not the location 'on the boulder', in which case the author would have written from there. Note that the close metonymic relation between a place and an entity (a placeholder) permits a choice between two anaphors, i.e. two visualizations. A similar example is (39):

(39) ... the floors and walls of the passage and the small room leading from it appeared to surge and lift (MCB_WFOW.ART)

in which passage, although a place-denoting noun, is referred to as an entity; this reification is perhaps due to the mention of its floors and walls (both being entities).

Alongside these instances of literal anaphora, there are also cases of metaphorical uses of from it. Consider (40), which might be assumed to involve some such metaphor as DIFFERENCE IS DISTANCE, cf. the use of long way:

(40) ... the Spanish language ... and Italian is not a long way from it (BNC fyj 0541)

If such a metaphor is indeed involved, we would expect the spatial notion of distance to impose the choice of the anaphor there. Similarly, it might be supposed that a metaphor such as FINANCIAL VIREMENT IS PHYSICAL TRANSFER is at play in (41):

(41) a reserve shall only be reduced to the extent that amounts transferred from it ... (BNC fej 0686)

However, we again do not find the anaphor there that characterized the metaphors identified in (28-36) above. The uses of prepositions before the complements of verbs, adjectives and nouns are also often assumed to derive 
from spatial metaphors, but again examples (42-44) evince the entity-referring it rather than place-referring there:

(42) Multiple sclerosis ... more women suffer from it than men (BNC $k b 1$ 1068)

(43) ... remained largely aloof from it all (MCA_IND4.SPO)

(44) ... excludes indifference to the group as well as alienation from it (MCB_MORF.BEL)

One of the fundamental problems of metaphor study is the identification in actual discourse of what is true metaphor as opposed to idiomatic expressions which may have their origins in metaphorical thinking but which no longer reflect metaphorical conceptualization (Steen 2005). It may be that the examination of anaphors of the type discussed here can provide a window upon this issue, in any case allowing a distinction between true and spurious instances of spatial or localistic metaphors.

Let us finally consider demonstrative anaphoric reference to entities, expressed in our corpus as from this, from that, from these and from those; we shall see that these cloud the issue somewhat. Concentrating on from that, we note that above all in the written language, the antecedent of from that is very often a second-order entity, as in (45) and (46):

(45) ... the notion of trust had become divorced from that of dependence ... (MCB_RTRU.SOC)

(46) ... using procedures quite different from those employed by Lawrence ... (MCB_PERC.MED)

Alternatively, the antecedent is a proposition, analysed in FG as a third-order entity:

(47) <being only 5 points behind $>$... but Toshack draws little comfort from that (MCA_IND4.SPO)

We also find that from that occurs in the kind of spurious metaphorical context identified in (40) above: 
(48) Homicide isn't far away from that (MCB_TREA.MED)

However, in the following cases, which seem to involve the well-established ACTIVITY IS A JOURNEY metaphors, we find from that rather than from there:

(49) They're given a medical, eyesight, hearing tests and going on from that er er a one day assessment ... (BNC jjw 0211)

(50) Enter to escape from that first (BNC g $4 k$ 0256)

(49) appears to rest upon the notion THE NEXT ACTION IS THE CONTINUATION OF A JOURNEY and (50) On OPERATING A COMPUTER IS JOURNEY, yet we find that rather than there in these two examples. The intimate metonymic relation between entities and places here warns us against relying too easily upon anaphors as a test for metaphoricality.

To conclude, then, it has been established that anaphora involves reference either to entities or to non-entities (qualities); in this article, we have focused on one particular type of quality, the circumstance 'place'. The close conceptual association between entities and the places they occupy (or between places and the entities that occupy them) readily allows metonymy in both directions, such that an entitydenoting expression can be used to refer to a place or vice versa. How we refer anaphorically to a phenomenon can be seen as reflecting how we visualize it. Consider Lakoff and Johnson's (1980: 35) classic example of metonymy:

(51) The ham sandwich is waiting for his check.

The possessive determiner his here contributes to the analysis of the ham sandwich as a metonymic reference to a person who has ordered one. Similarly, we have argued that the distinction between there and it/that reflects placereference and entity-reference respectively as two metonymically associated ways of visualizing phenomena. The corpus examination revealed that anaphoric there reflects the language user seeing the antecedent as a metaphorical location, whereas the occurrence of anaphoric it appeared to indicate a non-metaphorical view of the antecedent as an entity. This suggests that anaphors might be used as a test of metaphoricality where the source domain of the alleged metaphor is a matter of location or motion in spatial reality, e.g. UP/DOWN, JOURNEY, etc.; only where a place-anaphor is chosen can the expression be classified as metaphorical. 


\section{REFERENCES}

Anderson, J. M. 1971. The Grammar of Case: Towards a Localistic Theory. Cambridge etc.: Cambridge University Press.

Dik, S. C. 1997. The Theory of Functional Grammar. 2 parts. Berlin \& New York NY: Mouton de Gruyter.

Frawley, W. 1992. Linguistic Semantics. Hillsdale NJ, Hove and London: Erlbaum. Hengeveld, K. 1992. Non-Verbal Predication: Theory, Typology, Diachrony. Berlin and New York NY: Mouton de Gruyter.

Hengeveld, K. and J. L. Mackenzie. 2006. "Functional Discourse Grammar." Encyclopedia of language and linguistics, $2^{\text {nd }}$ edition. Ed. K. Brown. Oxford: Elsevier. Vol. 4. 668-676.

Jammer, M. 1954. Concepts of Space: The History of Theories of Space in Physics. Cambridge MA: Harvard University Press.

Lakoff, G. 1987. Women, Fire, and Dangerous Things: What Categories Reveal about the Mind. Chicago IL and London: University of Chicago Press.

Lakoff, G. and M. Johnson. 1980. Metaphors we Live by. Chicago IL and London: University of Chicago Press.

Lyons, J. 1977. Semantics. 2 parts. London \& New York NY: Cambridge University Press.

Mackenzie, J. L. 1992. "Places and Things." Layered Structure and Reference in a Functional Perspective. Eds. M. Fortescue, P. Harder, and L. Kristoffersen. Amsterdam and Philadelphia PA: Benjamins. 253-276.

Mackenzie, J. L. 2001. "Adverbs and Adpositions: The Cinderella Categories of Functional Grammar”. Revista Canaria de Estudios Ingleses 42: 119-135.

Pérez Hernández, L. and F. Ruiz de Mendoza Ibáñez. 2001. "Towards a Pragmatically-Oriented Cognitive Functional Grammar". Revista Canaria de Estudios Ingleses 42: 187-214.

Steen, G. J. 2005. "What Counts as a Metaphorically Used Word? The Pragglejaz Experience." The Literal and Nonliteral in Language and Thought. Eds. S. Coulson and B. Lewandowska-Tomaszczyk. Frankfurt a.M. etc.: Peter Lang. 299-322.

Strawson, P. F. 1959. Individuals. London: Methuen.

Thrane, T. 1980. Referential-Semantic Analysis: Aspects of a Theory of Linguistic Reference. Cambridge etc.: Cambridge University Press.

Weigand, H. 1990. Linguistically motivated principles of knowledge base systems. Dordrecht: Foris. 